\title{
Research on the Procurement Model of Multiple-Supplier based on Genetic Algorithm
}

\author{
Heng Zhang ${ }^{1, a^{*}}$, Qiang Lin ${ }^{1, b}$, Weijun Zhai ${ }^{2, c}$, and Kun Zhang ${ }^{1, d}$ \\ ${ }^{1}$ Air Force Early Warning Academy, Wuhan, 430019, China \\ ${ }^{2}$ PLA 93502, Hohhot, 010051, China

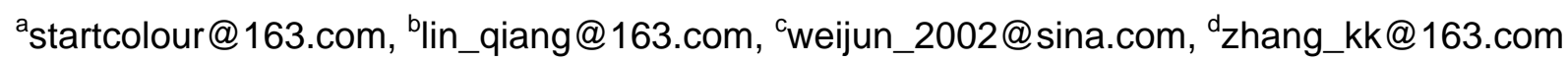

Keywords: Multiple-supplier, Procurement model, Relationship Management, Genetic algorithm

\begin{abstract}
According to the procurement under multiple-supplier, this paper evaluates the supplier quantitatively. Considering the factors of procurement cost and price discount, this paper establishes a procurement model based on the theories of relationship management. This model can give the optimal scheme and total cost under upper limit to procurement cost through resolving the model. It designs genetic algorithms to resolve the model. The optimization model can improve the quality and service level of materiel, establish long-term and steady relationships with suppliers.
\end{abstract}

\section{Introduction}

Modern supply chain theory believes that enterprises should focus on their core business, outsourcing non-core business, gain competitive advantage through the supply chain enterprises close cooperation [1]. Procurement is the initial stage of the supply chain, a key link of the whole supply chain. Therefore, procurement has become a hot issue in the study of supply chain.

With the change of market environment, competitive procurement has become the main mode of procurement; the enterprises often purchase under multiple-supplier [2]. Therefore, this paper establishes a multiple-supplier's procurement model. This model can select supplier and purchasing amount considering the factors of procurement cost, price discount and supplier's evaluation based on the theories of relationship management. This model can improve the quality and service level of materiel, establish long-term and steady relationships with suppliers.

\section{The Evaluation Of Supplier}

The evaluation of supplier is an important part in competitive procurement, the result of evaluation is the important basis of procurement.

The Indicator System Of Supplier Evaluation. According to the research status of relationship management, this paper summarizes usually evaluation factors of suppliers [3,4]. This paper designs the performance evaluation indicator system (Fig.1) based on product quality, after-sale service, production capacity, technical level and enterprises environment. 


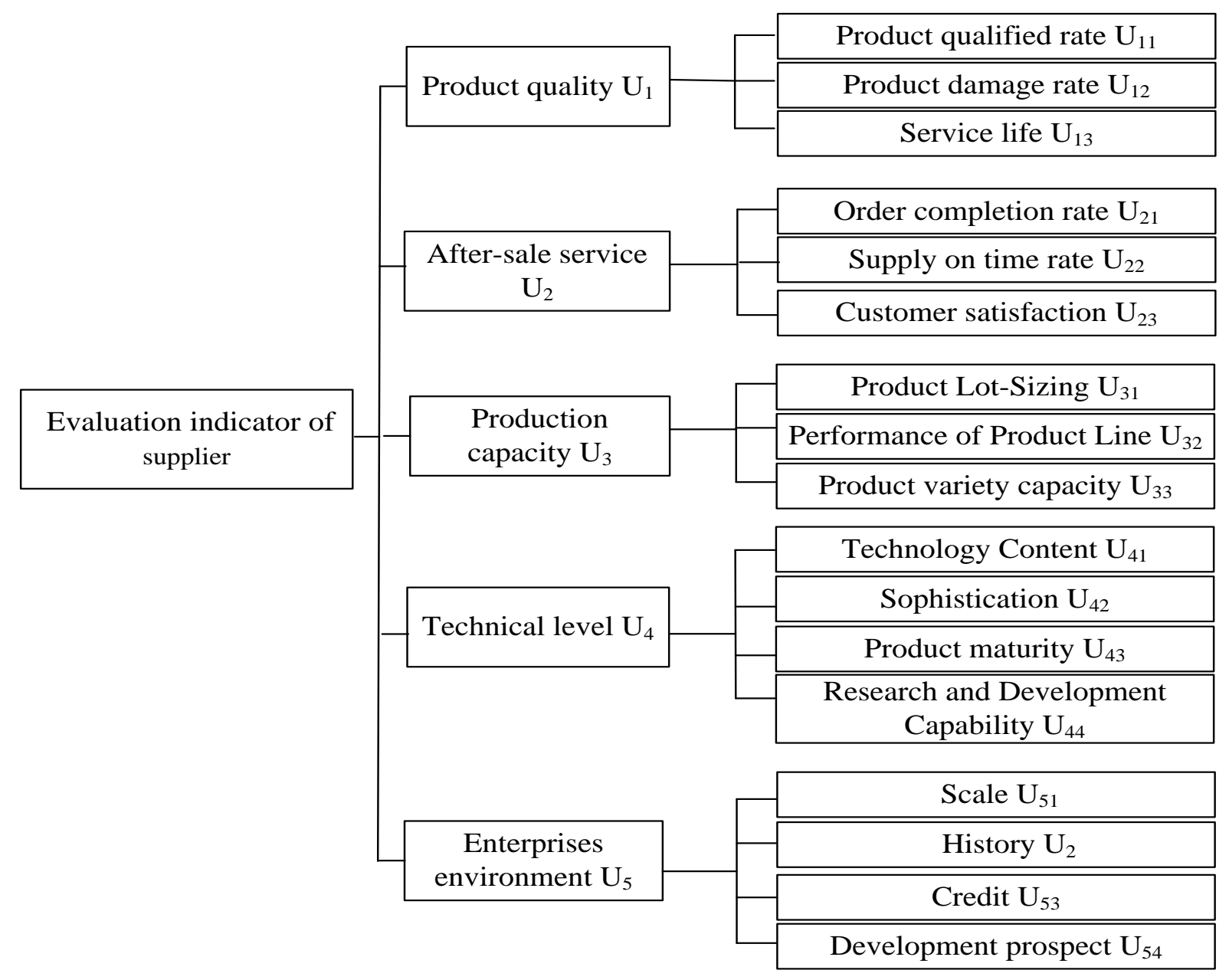

Fig.1. Evaluation indicator of supplier

The Evaluation Method Of Supplier .In evaluating supplier, many factors are involved, and they have fuzzy features in different extents and this paper proposes an evaluation index system for them. An evaluation method of supplier is built based on fuzzy AHP [5, 6].

The evaluation indicator of supplier has two grades, assume the first grades indicator is $\left(U_{1}, U_{2}, \cdots, U_{n}\right)$, the first grades indicator $j$ includes $U_{j}$ second indicators $\left(U_{j 1}, U_{j 2}, \cdots, U_{j q_{j}}\right)$.The weights of first and second grades indicators are $\omega_{i}$ and $\omega_{i j}$. The factor evaluation matrixes of first and second grades indicators are $\mathrm{X}$ and $X^{\prime}$.

The evaluation method of supplier calculates the value of performance evaluation. The basic steps are as follows:

1 The determination of indicator weights.

(1) Constructing the decision matrix of every grade indicators.

(2) Calculating the maximal eigenvalue and its eigenvectors.

(3) Educing the relative weights of every grade indicators.

(4) Consistency and error analysis in the decision matrix.

(5) Educing the first weights $\omega_{i}$ and the second grades indicators $\omega_{i j}$.

2 The single factor fuzzy evaluation.

(1) Constructing the factors and evaluation sets of every grade indicators.

(2) Setting up performance evaluation team and judging indicators.

(3) Educing the factor evaluation matrixes of second grades indicators $X^{\prime}$.

3 The fuzzy comprehensive evaluation.

(1) Educing $X_{i}$ according to Eq. 1.

(2) Educing $\mathrm{V}$ according to Eq. 2. 


$$
\begin{gathered}
X_{i}=\sum_{j=1}^{q_{j}} \omega_{i j} \cdot X_{i}^{\prime} \quad i=1,2, \cdots, n \\
V=\sum_{i=1}^{n} \omega_{i} \cdot X_{i}
\end{gathered}
$$

\section{The Procurement Model Of Multiple-Supplier Based On Genetic Algorithm}

Enterprises usually give priority to purchasing raw materials from cheaper suppliers; therefore, most of the procurement model of optimization designs based on cost.

In the purchase of key materials, enterprises are also willing to use high quality, good after-sales service product, more willing to work with higher management level and technical ability, not only just consider the procurement cost and price discount [7].

The Establishment Of Model. In order to establish purchasing model, this paper makes the following assumptions:

(1) There are $n$ suppliers which can provide a certain type of product, The supply ability of supplier is $p_{i}(i=1, \cdots, n)$. The procurement amount of products is $E$, which is greater than any of the supplier's supply ability, $E>p_{i}$. So, the procurement amount of each supplier is $x_{i}(i=1, \cdots, n)$.

(2) The procurement cost includes both direct costs $C$ and indirect costs $C^{\prime}$. Direct costs are paid directly to the supplier, mainly related to the procurement amount and production cost; Indirect cost refers to the management coordination cost in the purchasing stage, mainly related to the number of suppliers. The upper limit of procurement cost is Cost .

(3)The comprehensive evaluation result of supplier is $V_{i}(i=1, \cdots, n)$.

According to the above hypothesis, the model optimizes the purchase amount of each supplier, reflects the thought of prior purchasing good supplier evaluation, establishing the objective function is:

$$
\begin{gathered}
\underset{x}{\operatorname{Max}} F(x)=V_{1} * x_{1}+V_{2} * x_{2}+\cdots+V_{n} * x_{n} \\
\text { s.t. } C+C^{\prime} \leq \text { Cost } \\
\sum_{i=1}^{n} x_{i}=E \\
0 \leq x_{i} \leq p_{i}
\end{gathered}
$$

\section{Cost Analysis}

Direct Costs. The direct costs per unit product is $c_{i}$. When there is no discount, the direct costs $C=\sum_{i=1}^{n} Q_{i} \cdot C_{i}$. The actual situation, the greater the purchase amount, the bigger the discount, set $d_{i}$ as the discount.

$$
d_{i}=\left\{\begin{array}{cc}
d_{i}^{1} & 0<x_{i}<x_{1}^{i} \\
\vdots & \\
d_{\alpha}^{i} & Q_{\alpha-1}^{i}<x_{i}<x_{\alpha}^{i} \\
\vdots &
\end{array}\right.
$$

Where $0<x_{\alpha-1}^{i}<x_{\alpha}^{i}, 0<d_{\alpha-1}^{i}<d_{\alpha}^{i}$. The direct costs after the discount is as follows:

$$
C=\sum_{i=1}^{n} x_{i} * c_{i} *\left(1-d_{i}\right)
$$

Discussing the relationship between the direct costs and purchase amount, assumptions: 
(1) The product market is a buyer's market, the buyer has the absolute dominance, suppliers try to conclude the transaction;

(2) The number of suppliers is decided by the buyer independently;

(3) Information symmetry between the buyer and supplier, the supplier know the buyer's order and how many suppliers at the same time;

(4) The marginal cost of each supplier is the same.

On the basis of the above assumptions, using cournot duopoly model calculate the price after discount [8].

$$
c_{i}=\frac{a_{i}+k e}{k+1}
$$

Type: $a_{i}$ is the exogenous variables of per unit product cost, $e$ is the per unit product cost, $k$ is the number of suppliers. When $k \rightarrow \infty, c_{i} \rightarrow e$.That is, due to competition, resulting in a decline in prices.

The direct costs for procurement

$$
C=\sum_{i=1}^{n} x_{i} * \frac{a_{i}+k e}{k+1} *\left(1-d_{i}\right)
$$

Indirect Costs. Indirect cost refers to the management coordination cost in the purchasing stage, mainly related to the number of suppliers, can be written to $C^{\prime}=f(k)$.

The Solution Of The Model. When the number of supplier and purchasing amount is small, the integer programming, the lagrangian relaxation method and Benders decomposition method and other methods can solve the model. With the increase of the number of supplier and purchasing amount, the solution efficiency of these algorithms will rapidly reduce [9]. In view of the genetic algorithm in solving the complex nonlinear optimization problem of significant advantages, this paper designs genetic algorithms to resolve the model.

The basic idea of solving the objective function Eq. 3 using genetic algorithm is as following: Determine the decision variables $x=\left[x_{1}, x_{2}, \cdots, x_{n}\right]$, which assigned to each supplier purchasing amount; Randomly generating initial population, the individuals in a population for different procurement scheme; , In turn, can be calculated by the objective function value, the fitness of the individuals, to punish does not meet the constraints of the individual; At the same time to this population of selection, crossover and mutation genetic algorithm, such as after several iterations, algorithm is expected to converge to the optimal purchasing scheme.

\section{Examples}

The enterprise need some products, 4 million a year, there are eight suppliers can provide this kind of products. Experts using the analytic hierarchy process (AHP), to determine the supplier evaluation index weight coefficient, and the indicators of eight suppliers single factor evaluation, data as shown in table 1 . If the purchase amount under 0.2 million, there is no discount. If the purchase amount is between 0.2 million and 0.4 million, the discount rate is $1 \%$. If the purchase amount is between 0.4 million and 0.8 million, the discount rate is $1.5 \%$. If the purchase amount is between 0.8 million and 1 million, the discount rate is $3 \%$. If the purchase amount above 1 million, the discount rate is $4 \%$. The maximum supply amount of each supplier is 1.4 million. The exogenous variables of per unit product cost: $a_{1}=7.8, a_{2}=4.5, a_{3}=5, a_{4}=3.7, a_{5}=6.5, a_{6}=4, a_{7}=3, a_{8}=4.9$. The function of Indirect costs: $f(k)=20+12 k$. The per unit product cost: RMB 3.3. The upper limit of procurement cost: RMB 14.5 million.

According to the Eq. 1 and Eq. 2, we can get the comprehensive evaluation results: $V=[0.9106,0.8464,0.8598,0.8194,0.8677,0.8366,0.7623,0.8551]$. 
Table 1. Single factor evaluation index weights and data tables

Indictor and Weight

Data

\begin{tabular}{cccccccccc}
\hline $\begin{array}{c}\text { First } \\
\text { indictors }\end{array}$ & $\begin{array}{c}\text { Second } \\
\text { indicators }\end{array}$ & $\mathrm{A}_{1}$ & $\mathrm{~A}_{2}$ & $\mathrm{~A}_{3}$ & $\mathrm{~A}_{4}$ & $\mathrm{~A}_{5}$ & $\mathrm{~A}_{6}$ & $\mathrm{~A}_{7}$ & $\mathrm{~A}_{8}$ \\
\hline \multirow{3}{*}{$\mathrm{U}_{1}(0.453)$} & $\mathrm{U}_{11}(0.515)$ & 0.98 & 0.9 & 0.93 & 0.92 & 0.88 & 0.97 & 0.72 & 0.92 \\
& $\mathrm{U}_{12}(0.354)$ & 0.95 & 0.89 & 0.91 & 0.71 & 0.95 & 0.88 & 0.71 & 0.85 \\
& $\mathrm{U}_{13}(0.131)$ & 0.92 & 0.85 & 0.75 & 0.75 & 0.92 & 0.87 & 0.72 & 0.85 \\
$\mathrm{U}_{2}(0.211)$ & $\mathrm{U}_{21}(0.402)$ & 0.85 & 0.83 & 0.78 & 0.78 & 0.85 & 0.84 & 0.78 & 0.87 \\
& $\mathrm{U}_{22}(0.252)$ & 0.92 & 0.89 & 0.83 & 0.83 & 0.72 & 0.86 & 0.73 & 0.84 \\
& $\mathrm{U}_{23}(0.346)$ & 0.95 & 0.75 & 0.96 & 0.96 & 0.95 & 0.85 & 0.76 & 0.91 \\
$\mathrm{U}_{3}(0.114)$ & $\mathrm{U}_{31}(0.412)$ & 0.83 & 0.87 & 0.75 & 0.75 & 0.83 & 0.77 & 0.85 & 0.92 \\
& $\mathrm{U}_{32}(0.226)$ & 0.88 & 0.83 & 0.88 & 0.85 & 0.88 & 0.73 & 0.75 & 0.82 \\
& $\mathrm{U}_{33}(0.362)$ & 0.87 & 0.86 & 0.86 & 0.87 & 0.87 & 0.66 & 0.86 & 0.84 \\
& $\mathrm{U}_{41}(0.245)$ & 0.92 & 0.84 & 0.82 & 0.82 & 0.72 & 0.54 & 0.82 & 0.71 \\
$\mathrm{U}_{4}(0.112)$ & $\mathrm{U}_{42}(0.232)$ & 0.93 & 0.85 & 0.81 & 0.80 & 0.75 & 0.57 & 0.84 & 0.77 \\
& $\mathrm{U}_{43}(0.204)$ & 0.81 & 0.76 & 0.89 & 0.74 & 0.86 & 0.79 & 0.73 & 0.69 \\
& $\mathrm{U}_{44}(0.319)$ & 0.83 & 0.72 & 0.88 & 0.78 & 0.83 & 0.72 & 0.78 & 0.67 \\
& $\mathrm{U}_{51}(0.364)$ & 0.84 & 0.73 & 0.79 & 0.79 & 0.84 & 0.83 & 0.89 & 0.71 \\
$\mathrm{U}_{5}(0.110)$ & $\mathrm{U}_{52}(0.150)$ & 0.8 & 0.86 & 0.73 & 0.82 & 0.8 & 0.76 & 0.92 & 0.78 \\
& $\mathrm{U}_{53}(0.381)$ & 0.78 & 0.75 & 0.73 & 0.79 & 0.78 & 0.65 & 0.89 & 0.93 \\
& $\mathrm{U}_{54}(0.105)$ & 0.87 & 0.86 & 0.78 & 0.58 & 0.87 & 0.86 & 0.48 & 0.90 \\
\hline
\end{tabular}

Genetic algorithm of parameter Settings are as follows: population size $N=400$; The maximum number of iterations are 4000; Crossover probability is 0.7 ; The mutation probability is 0.1 . Using the Matlab programming, the optimal purchasing scheme is: $x_{1}=453450, x_{2}=1069612, x_{3}=1383399$, $x_{4}=2009, x_{5}=749, x_{6}=3760, x_{7}=0, x_{8}=1087021$. The total purchasing cost is RMB 14.497377 million. The objective function value, the population mean in relation to the change of the number of iterations are shown in Fig 2.

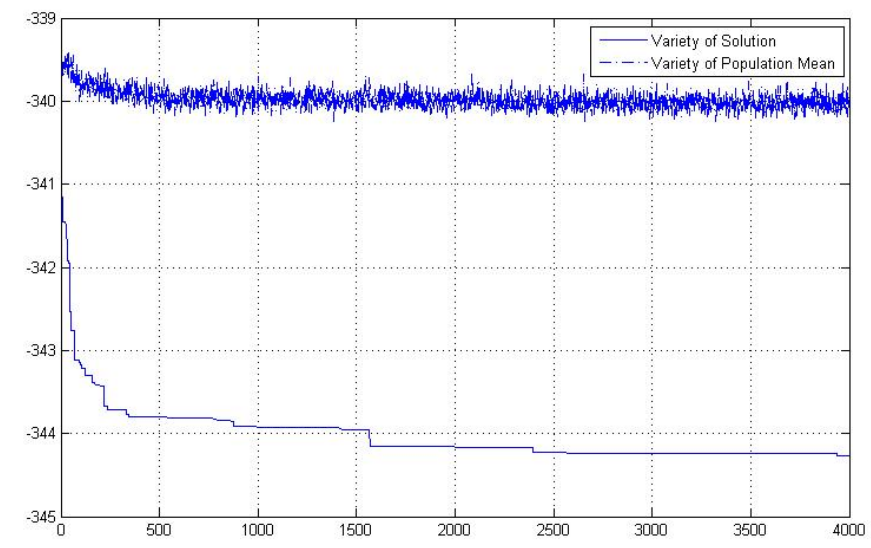

Fig. 2. Objective function value and the graph is the number of population mean genetic algorithm with system

\section{Summary}

In a competitive, cooperative and dynamic market environment, competitive procurement is the necessary way of purchasing. Therefore, this paper establishes a key products procurement model based on the theories of relationship management. According to the characteristics of key products procurement, this model considers the factors of procurement cost, price discount and the evaluation 
of supplier. This model helps to improve the level of guarantee product quality and service, and suppliers to establish long-term, stable relations of cooperation.

\section{References}

[1] Ma Shi hua, Lin Yong. Supply Chain Management, fourth ed., Higher Education Press, Beijing, 2015.

[2] Huo B, Zhao X, Zhou H. The Effects of Competitive Environment on Supply Chain Information Sharing and Performance: An Empirical Study in China [J]. Production and Operations Management, 2014, 23(4)552-569.

[3] Yu W, Jacobs M A, Salisubury W D, et al. The Effects of Supply Chain Integration on Customer Satisfaction and Financial Performance: An organizational Learning Perspective [J]. International Journal of Production Economics, 2013, 146(1)346-358.

[4] XIANG Wei, SONG Fa-shuai, YE Fei-fan. Simulation on Production Load Equilibrium Order Allocation within Multi-suppliers [J]. Journal of System Simulation, 2013, 25(2)209-215.

[5] HANG Shu-liang, CHEN You-ling, ZHANG Dou. Supplier Selection and Decision Method in Supply Chain Management [J]. Application Research of Computers, 2015, 23(4)1024-1027.

[6] SAWIK T. Integrated Selection of Suppliers and Scheduling of Customer Orders in the Presence of Supply Chain Disruption Risk [J]. International Journal of Production Research, 2013,13(1)4045-4069.

[7] Song Li jun, Zhao Hu, Zhou kang qu. Process of customer collaborative supplier selection based on rough set theory and wavelet neural network [J]. Computer Integrated Manufacturing Systems, 2014, 120(12)3150-3159.

[8] ZHANG Shu-liang, CHEN You-ling, ZHANG Dou. Supplier Selection and Decision Method in Supply Chain Management [J]. Application Research of Computers, 2015, 32(4) 1024-1031.

[9] DING Xi-hai, WANG Li-ya. Study on the Model and Algorithm of Multiple-sourcing with the Consideration of Transporters [J]. Industrial Engineering and Management, 2012, 17(2)68-72. 